\title{
Comparative molecular analysis of strains of the Aleutian Disease Virus isolated from farmed and wild mink
}

\author{
Andrzej Jakubczak', Marek Kowalczyk', Krzysztof Kostro², Grazyna Jezewska-Witkowska' \\ ${ }^{1}$ Department of Biological Basis of Animal Production, Faculty of Biology and Animal Breeding, University of Life Sciences, \\ Lublin, Poland \\ ${ }^{2}$ Department of Epizootiology and Clinic of Infectious Diseases, Faculty of Veterinary Medicine, University of Life Sciences, \\ Lublin, Poland
}

Jakubczak A, Kowalczyk M, Kostro K, Jezewska-Witkowska G. Comparative molecular analysis of strains of the Aleutian Disease Virus isolated from farmed and wild mink. Ann Agric Environ Med. 2017; 24(3): 366-371. doi: 10.26444/aaem/75688

\begin{abstract}
I Abstract
Introduction and objective. Aleutian Disease is a significant biological factor causing substantial losses in mink farming. The virus inducing the disease also infects wild populations which may constitute an asymptomatic reservoir. To compare genetic variants of the AMD virus occurring in wild and farmed mink populations, an analysis was performed on a fragment of the VP2 protein sequence of the virus infecting both populations, taken from different living environments.

Material and method. Genetic material was isolated from 11 farmed animals in which anti-AMDV antibodies had been detected and from 20 wild animals. The DNA obtained was amplified using primers specific for the fragment encoding the VP2 protein. The product obtained was sequenced and bioinformatic analysis was performed.

Results. Viral material was detected in 11 farmed and 7 free-living animals. Similarity of sequences averaged $99 \%$ within groups and $94 \%$ between groups. The sequencing results made it possible to identify characteristic changes for each group. In the isolates from the wild animals, the following changes were observed in the epitope region with respect to the reference sequence: C3704T, G3710A, T3722C, T3746C and A3749G. In the isolates from the farmed animals a G3779A transition was noted. Phylogenetic analysis showed that the variants infecting the two groups occupy separate branches of the phylogenetic tree.
\end{abstract}

Conclusion. The variants of the virus infecting the two groups may have a common origin, but at present they constitute two separate groups, with characteristic differences making it possible to recognize their genotype.

\section{Key words}

AMDV, VP2 protein, molecular phylogenetics, mink

\section{INTRODUCTION}

One of the most serious health threats for farmed mink is Aleutian Disease (AD), induced by a non-enveloped parvovirus of the genus Amdovirus. Aleutian Disease may take the form of a transient asymptomatic infection, but infections are usually persistent, sometimes even causing death $[1,2]$. The course of the disease is mainly determined by the variant of animal and the virulence ofthe infecting virus. Isolated strains have varying pathogenicity, from the non-pathogenicstrain AMDV G, to the low-virulence strain SL-3 isolated in Germany, the Pullman strain which is lethal for the Aleutian variety of mink, and the highly lethal Utah strain $[3,4]$.

Aleutian Disease, apart from economic losses affecting breeding farms [5], may also have a significant impact on free-living mink populations. Research indicates frequent AMDV infections in wild animal populations, specifically in American mink (Neovison vison), European polecat (Mustela putorius), European pine marten (Martes martes), common genet (Genetta genetta) [6,7], and even raccoon dogs (Nyctereutes procyonoides) and skunks (Mephitis mephitis)

Address for correspondence: Andrzej Jakubczak, Department of Biological Basis of Animal Production, Faculty of Biology and Animal Breeding, University of Life Sciences, Akademicka 13, 20-950 Lublin, Poland

E-mail: andrzej.jakubczak@up.lublin.pl

Received: 27 April 2016; accepted: 15 May 2017; first published: June 2017
[8], which can be an asymptomatic reservoir of AMD. There have also been reports of the possibility of humans becoming infected with AMDV. To-date, two cases of infection have been described in employees of a farm on which the virus was present [9], which indicates that it has certain zoonotic properties.

The genome of the virus consists of ssDNA $4.8 \mathrm{~kb}$ in length [10], containing information about three non-structural proteins (NS1, NS2 and NS3) and two structural proteins (VP1 and VP2) [5]. The non-structural proteins are responsible for expression of viral material, while the structural proteins determine antigenic properties. Of particular importance is the protein VP2, containing a hypervariable region with amino acids specific for particular strains [11]. The hypervariable region, due to its localization in the tertiary structure of capsid proteins, may play a key role in both the affinity of the virus for specific tissues and its antigenic properties. Polymorphism in the hypervariable region enables differentiation of strains with varying pathogenicity [12]. The amino acid sequence in this protein may have a significant effect on the range of hosts infected [13], as in the case of CPV-2 [14, 15]. The VP2 protein region containing epitopes, due to its significance in pathogenesis as well as its potentially high variability, seems to be a good site in the genome for analysis of polymorphism of the virus in farmed and wild mink populations. According to some researchers, Aleutian Disease was brought to Europe together 
with American mink and has played a significant role in reducing the European mink population $[7,16]$. However, there are still no persuasive arguments that could definitively confirm or rule out the possibility of the circulation of AMDV between populations of farmed and free-living animals. The presence of anti-AMDV antibodies does not entirely confirm the circulation of the virus between mink populations, but only the occurrence of infections in both groups. A key question is whether isolates found in wild and farmed mink populations are different genetic variants of the virus, and if so, what is their origin?

\section{OBJECTIVES}

To compare genetic variants of AMDV in free-living and farmed mink populations, analysis was made of a fragment of the VP2 protein sequence of AMDV infecting both populations, taken from different living environments. The aim of the study was to determine the degree to which isolates from wild and farmed individuals are similar, as well as their phylogenetic relationship with sequences from other countries.

\section{MATERIALS AND METHOD}

Sample collection. Biological material from two groups of animals, farmed and free-living mink, was used for the analyses.

Farmed mink were obtained from two farms on which the occurrence of the persistent, subclinical form of Aleutian disease was confirmed by counter-current immunoelectrophoresis (CIEP). Anti-AMDV antibodies were detected in $60 \%$ of the animals tested. Eleven individuals confirmed to be infected were selected for the analyses. The biological material for serological diagnosis of AMDV consisted of blood samples collected from live farmed animals into capillary tubes by toe nail clipping. The study was performed according to statutory bioethical standards and approved by the Local Ethics Commission of the University of Life Sciences in Lublin (Approval No. $83 / 2009$ ).

Wild animals were legally harvested by licensed professional trappers in north-eastern Poland, for purposes unrelated to this study. The biological material collected from the wild animals $(n=20)$ consisted of samples of internal organs (spleen and retropharyngeal lymph nodes) and blood. Post mortem material for genotyping of AMDV consisted of samples of internal organs (spleen and retropharyngeal lymph nodes) collected from farmed animals during the planned slaughter period - the first half of December.

DNA isolation. DNA was extracted from the spleen, which was cut into small pieces of $5 \mathrm{mg}$. Tissues were lysed using Tissue Lyser II (QIAGEN) for $5 \mathrm{~min}$. at a frequency of 30 $1 / \mathrm{s}$, with $200 \mathrm{ul}$ of ATL buffer added to the sample. DNA was isolated with a DNeasy Blood and Tissue kit (QIAGEN), according to the manufacturer's protocol.

PCR amplification and sequencing. A fragment of the VP2 sequence was amplified using the forward primer 5'TCTAGATTGGGCCTACCTCCTCTCTG3' and the reverse primer 5'ATACAGGACCAACGTTGTCT3', according to Costello et al. [17]. The reactions $(25 \mu \mathrm{L}$ total volume) contained $2 \mu \mathrm{l}$ DNA and $1.5 \mathrm{U}$ Taq polymerase (AmpliTaq Gold 360 DNA Polymerase, Applied Biosystems) in the manufacturer's buffer, adjusted to a final concentration of $2 \mathrm{mM} \mathrm{MgCl} 2,0.8 \mathrm{mM}$ of each dNTP and $0.8 \mathrm{mM}$ of each primer. PCR cycling conditions were $95^{\circ} \mathrm{C}$ for $10 \mathrm{~min}$, 40 cycles of $95^{\circ} \mathrm{C}$ for $30 \mathrm{~s}, 53^{\circ} \mathrm{C}$ for $45 \mathrm{~s}, 72^{\circ} \mathrm{C}$ for $60 \mathrm{~s}$, and $72^{\circ} \mathrm{C}$ for $10 \mathrm{~min}$ (Labcycler, SensoQuest). To confirm the PCR products, gel electrophoresis was carried out using $2 \%$ agarose gel with ethidium bromide (EtBr). The PCR product was purified using an ExoSAP-IT kit (Affymetrix). The second amplification (sequencing PCR) - bidirectional sequencing - was carried out with a BigDye ${ }^{\circledast}$ Terminator v3.1 CycleSequencing Kit (Applied Biosystems). PCR products were purified using a DyeEx Spin Kit (Qiagen) in a QIAcube. PCR products were sequenced using a 3100 Genetic Analyzer (Applied Biosystems).

Bioinformatic processing. The sequences were processed using DNA Baser [DNA Baser Sequence Assembler v4.x (2014), Heracle BioSoft]. The sequences obtained were edited to a length of 453 nucleotides. Nucleotide sequences were translated to amino acid sequences using MEGA 6 software (yielding a fragment of 150 amino acids). All sequences were deposited in the GenBank. NC_001662.1 was selected as a reference sequence, as in a previous study by Jahns et al [18]. This sequence belongs to a non-pathogenic strain, therefore changes with respect to pathogenic strains are highlighted. The choice of this sequence shows the high variability existing among isolates of AMDV. Assembly, alignment and comparison of nucleotide and amino acid sequences were performed using MEGA 6 software. Epitope regions were identified on the basis of data from the Immune Epitope Database and Analysis Resource (IEDB) (http:// www.iedb.org/) and a study by Costello [17]. A phylogenetic tree was prepared by MEGA 6 using the maximum likelihood method with 1,000 bootstrap replicates. Visualization of the tree was prepared using FigTree 1.4.2 software.

\section{RESULTS}

Viral genetic material was detected using PCR in the case of 7 samples from wild animals and 11 samples from farmed minks. Similarity of nucleotide sequences of variants of the virus from farmed and wild animals were compared with a non-pathogenic strain. Similarity within the two groups (wild and farmed) was high at 99\%, and similarity between the groups averaged $94 \%$ (Tab. 1).

There were 35 differences in the nucleotide sequence between isolates from the wild and farmed animals, among which 20 involved single changes in a codon, 6 caused a change in two nucleotides in a codon, and 9 led to changes in the sequence of three entire codons (Tab. 2). Changes in the nucleotide sequence cause 9 changes in the amino acid sequence.

Using the Immune Epitope Database and Analysis Resource (IEDB) (http://www.iedb.org/) and a study by Costello [17], two epitope regions were distinguished in the analysed sequence (Tab. 3): the first, considered by Costello to be dominant, in the S428-T448 region of the amino acid sequence, and the second in the K455-H471 region. 
Table 1. Similarity matrix between isolates from wild and farmed animals and the non-pathogenic strain

\begin{tabular}{|c|c|c|c|c|c|c|c|c|c|}
\hline Variant of virus & AMDV-G & wild_1 & wild_2 & wild_3 & wild_4 & ferm_1 & ferm_2 & ferm_3 & ferm_4 \\
\hline wild_1 & 0.944 & & & & & & & & \\
\hline wild_2 & 0.947 & 0.997 & & & & & & & \\
\hline wild_3 & 0.942 & 0.991 & 0.993 & & & & & & \\
\hline wild_4 & 0.944 & 0.995 & 0.997 & 0.995 & & & & & \\
\hline farm_1 & 0.949 & 0.938 & 0.94 & 0.944 & 0.942 & & & & \\
\hline farm_3 & 0.953 & 0.942 & 0.944 & 0.949 & 0.947 & 0.995 & 0.997 & & \\
\hline farm_4 & 0.944 & 0.933 & 0.935 & 0.94 & 0.938 & 0.995 & 0.993 & 0.991 & \\
\hline farm_5 & 0.942 & 0.931 & 0.933 & 0.938 & 0.935 & 0.988 & 0.991 & 0.988 & 0.984 \\
\hline
\end{tabular}

Variant in italics - similarity within groups wild and farmed; bold - similarity between groups

Table 2. Differences in the nucleotide and amino acid sequence between isolates from wild and farmed animals

\begin{tabular}{|c|c|c|c|c|c|c|c|}
\hline \multirow{2}{*}{$\begin{array}{c}\text { Position in } \\
\text { nucleotide } \\
\text { sequence }\end{array}$} & \multicolumn{3}{|c|}{ Nucleotide } & \multirow{2}{*}{$\begin{array}{l}\text { Position in } \\
\text { amino acid } \\
\text { sequence of } \\
\text { VP2 protein }\end{array}$} & \multicolumn{3}{|c|}{ Amino Acid } \\
\hline & AMDV-G & Farm & Wild & & AMDV-G & Farm & Wild \\
\hline 3395 & $\mathrm{~T}$ & C & $\mathrm{T}$ & 330 & D & D & D \\
\hline 3396 & A & C & A & 331 & $\mathrm{~N}$ & $\mathbf{H}$ & $\mathrm{N}$ \\
\hline 3401 & $C$ & $\mathrm{~T}$ & $C$ & 332 & $\mathrm{~T}$ & $\mathrm{~T}$ & $\mathrm{~T}$ \\
\hline 3425 & G & $\mathrm{G} / \mathrm{A}$ & G & 340 & $E$ & $E$ & $E$ \\
\hline $3480^{*}$ & $\mathrm{~T}$ & A & $\mathrm{T}$ & \multirow{3}{*}{359} & \multirow{3}{*}{$Y$} & \multirow{3}{*}{ M } & \multirow{3}{*}{$Y$} \\
\hline $3481^{*}$ & A & $\mathbf{T}$ & A & & & & \\
\hline $3482^{*}$ & $C$ & G & $C$ & & & & \\
\hline 3512 & G & G & A & 369 & G & G & G \\
\hline 3513 & $\mathrm{~T}$ & $\mathrm{~T}$ & C & 370 & $\mathrm{~L}$ & L & $\mathrm{L}$ \\
\hline 3536 & A & A & G & 377 & G & G & G \\
\hline $3582^{*}$ & A & $\mathrm{T}$ & $\mathrm{A} / \mathrm{T}$ & \multirow{3}{*}{393} & \multirow{3}{*}{$\mathrm{S}$} & \multirow{3}{*}{$S$} & \multirow{3}{*}{$\mathrm{S} / \mathrm{T}$} \\
\hline $3583^{*}$ & G & C & $\mathrm{G} / \mathrm{C}$ & & & & \\
\hline $3584^{*}$ & $\mathrm{~T}$ & $\mathrm{~T}$ & C & & & & \\
\hline 3587 & A & A & G & 394 & Q & Q & $\mathrm{Q}$ \\
\hline 3617 & $C$ & $\mathrm{C} / \mathrm{T}$ & $C$ & 404 & $Y$ & $Y$ & $\mathrm{Y}$ \\
\hline 3620 & $C$ & $\mathrm{C} / \mathrm{T}$ & $C$ & 405 & 1 & 1 & 1 \\
\hline 3629 & A & $A / G$ & A & 408 & $\mathrm{R}$ & $\mathrm{R}$ & $\mathrm{R}$ \\
\hline 3650 & G & A & G & 415 & $E$ & $E$ & $E$ \\
\hline $3657^{*}$ & $C$ & C & $\mathrm{T}$ & \multirow{3}{*}{418} & \multirow{3}{*}{ L } & \multirow{3}{*}{$\mathrm{L} / \mathrm{H}$} & \multirow{3}{*}{$\mathrm{L}$} \\
\hline $3658^{*}$ & $\mathrm{~T}$ & T/A & $\mathrm{T}$ & & & & \\
\hline $3659^{*}$ & A & $A / T$ & A & & & & \\
\hline $3702^{* *}$ & G & $\mathrm{G} / \mathrm{C}$ & G & \multirow{2}{*}{433} & \multirow{2}{*}{ D } & \multirow{2}{*}{$\mathrm{D} / \mathrm{H}$} & \multirow{2}{*}{$\mathrm{D}$} \\
\hline $3704^{* *}$ & $C$ & $C$ & $\mathrm{~T}$ & & & & \\
\hline 3710 & G & G & A & 435 & $E$ & $E$ & $E$ \\
\hline 3722 & $\mathrm{~T}$ & $\mathrm{~T}$ & $C$ & 439 & $\mathrm{H}$ & $\mathrm{H}$ & $\mathrm{H}$ \\
\hline $3745^{* *}$ & G & G & C/A & \multirow{2}{*}{447} & \multirow{2}{*}{$\mathrm{R}$} & \multirow{2}{*}{$\mathrm{R}$} & \multirow{2}{*}{$\mathbf{P} / \mathbf{H}$} \\
\hline $3746^{* *}$ & $\mathrm{~T}$ & $\mathrm{~T}$ & $C$ & & & & \\
\hline $\begin{array}{c}3747^{* *} \\
3749\end{array}$ & $\begin{array}{l}A \\
A\end{array}$ & $\begin{array}{c}A / T \\
A\end{array}$ & $\begin{array}{c}\mathrm{A} / \mathrm{T} \\
\mathrm{G}\end{array}$ & 448 & $S$ & $S / T$ & $\mathrm{~S} / \mathrm{T}$ \\
\hline 3752 & A & G & A & 449 & $\mathrm{P}$ & $\mathrm{P}$ & $P$ \\
\hline 3755 & $C$ & $C$ & G & 450 & $\mathrm{P}$ & $\mathrm{P}$ & $P$ \\
\hline 3756 & A & A & G & 451 & 1 & 1 & $\mathbf{v}$ \\
\hline 3779 & G & $A$ & G & 458 & $S$ & $S$ & $S$ \\
\hline 3788 & A & $\mathrm{G} / \mathrm{A}$ & A & 461 & $E$ & $E$ & $E$ \\
\hline 3827 & $\mathrm{~T}$ & T/A & $\mathrm{T}$ & 474 & D & $\mathrm{D} / \mathrm{E}$ & $\mathrm{D}$ \\
\hline
\end{tabular}

Position with index ${ }^{*}$ - changes affecting the entire codon; Position with index ${ }^{*}$ - change within the codon; changes in bold are nonsynonymous; $A / B$ - occurrence of two variants $A$ and $B$ in the group
Comparison of epitope sequences indicates high variability in the regions interacting with antibodies, with specific changes occurring in both groups. In the region of the first epitope, five changes characteristic of isolates from free-living individuals were noted: C3704T, G3710A, T3722C, T3746C and $\mathrm{A} 3749 \mathrm{G}$, all of which were transitions. In the sequence of the second epitope, a change was observed inG3779A, appearing exclusively in farmed individuals. In the case of both groups, changes differentiating them from the nonpathogenic strain were observed: A3705C (transversion caused a change in amino acid N434H), A3747T (transversion caused a change in amino acid T448S), and A3770G, which was synonymous. A nonsynonymous $\mathrm{G} 3702 \mathrm{C}$ change occurred in two farm variants, causing a change in amino acid D433H. High variability was noted in the case of isolates from the wild population in nucleotide 3745 . In the nonpathogenic strain, guanine was present in this position. In three wild variants, a G3745A transition occurred which led to a change in amino acid $\mathrm{R} 447 \mathrm{H}$. One of the wild isolates was characterized by the nonsynonymous change in R447P, which was the effect of a G3745C transversion.

Phylogenetic analysis showed that the variants infecting the wild animals occupy a separate branch from the farm isolates (Fig. 1). High similarity with Polish isolates can be seen in variants isolated in Ireland, four of which occupy the same branch as the Polish variants occurring in free-living mink. Most closely related to the virus attacking farmed individuals are the strains from Russia and one of the Irish isolates.

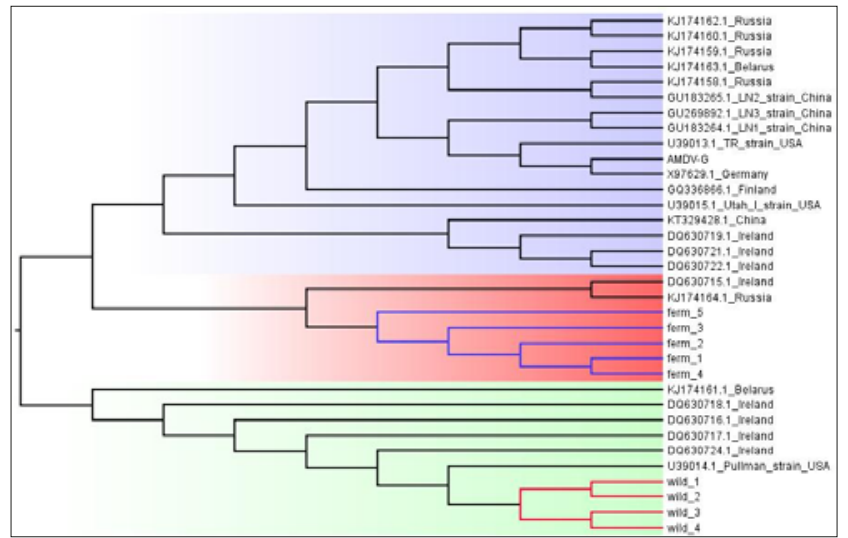

Figure 1. Phylogenetic tree prepared by MEGA 6 using the maximum likelihood method with 1,000 bootstrap replicates, representing relationships between isolates from farmed and wild animals. Isolates from farmed and wild animals occupy two different branches 


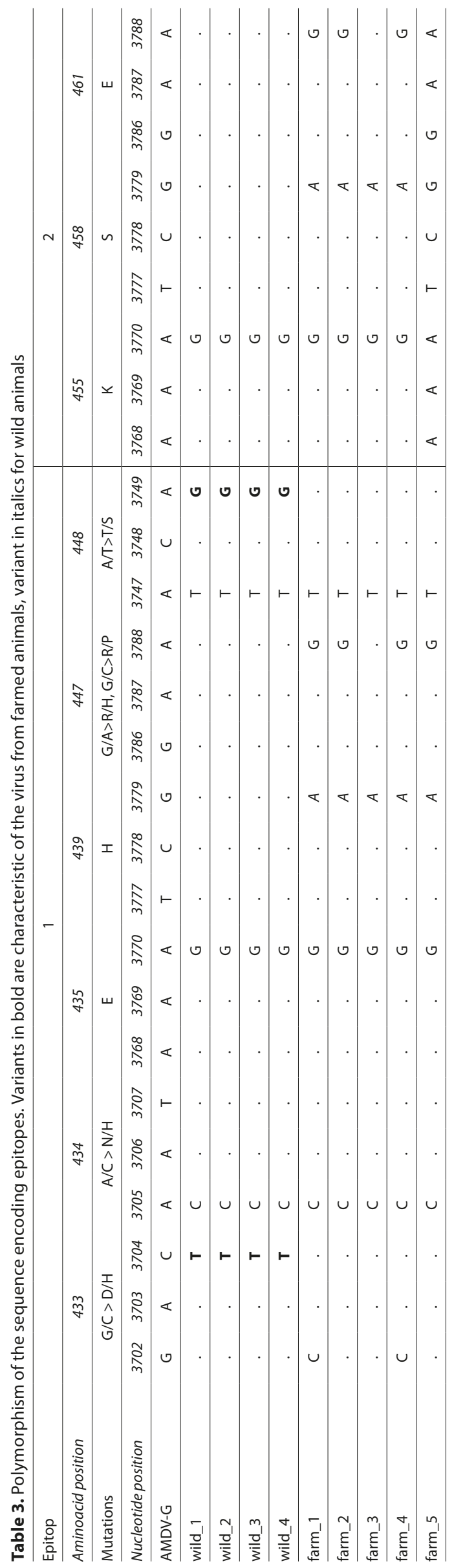




\section{DISCUSSION}

Both groups differed from the non-pathogenic strain to a similar degree (on average 6\%). The high differentiation in the case of parvoviruses is also confirmed by research on CPV-2, in the case of which numerous genetic variants may attack a single individual [19]. In the presented study, marked differences were observed between the wild and farmed groups. The farm variants of the virus, despite being derived from farms at a considerable distance from one another, exhibited high similarity, which clearly indicates a common original source of infection. The situation is similar in the case of wild mink, in which high homogeneity of the virus was observed despite their having been trapped at different locations. Both groups are about equally distant from the nonpathogenic strain, but display different directions of evolution.

Changes $\mathrm{N} 331 \mathrm{H}$ and $\mathrm{Y} 359 \mathrm{M}$ were characteristic for variants of the virus in the farmed animals, while the I451V change occurred only in the wild animals. It is worth noting codon 447, in which arginine is encoded in both the non-pathogenic strain and in the farmed animals, while in the case of the wild animals proline ( 1 animal) or histidine ( 6 animals) was encoded. Changes were also observed in single cases in each group, including S393T, occurring in one of the wild animals, and $\mathrm{L} 418 \mathrm{H}, \mathrm{D} 433 \mathrm{H}$ and $\mathrm{D} 474 \mathrm{E}$ in representatives of the farmed animals. Single changes in the amino acid sequence may be of key importance for pathogenicity; it is theorized that nonsynonymous changes in the gene encoding VP2 in FPLV led to the emergence of CPV-2 [20]. Substitutions in this protein led to the separation of variants $a, b$ and $c$, which supplanted the original strain; a change in just one amino acid enables differentiation of the pathogen into variants a and $\mathrm{b}[21]$.

The difference between amino acid sequences does not fully convey the polymorphism between the isolates, as the great majority of substitutions are synonymous. Mutations that do not alter the encoded amino acid do not change the translation product, but may affect its stability. Degeneration of the genetic code conditions generation of the same product from different codons, but during translation different codons encoding the same amino acids may differ in the speed of translation in the ribosome. In consequence, the rate of protein folding to higher-order structures is varied, which may result in proteins having the same amino acid sequence but different properties. The high degree of genetic dissimilarity is underscored by the fact that entire codons differed in the two groups.

The pathogenicity of the virus may be strongly influenced by changes in the epitope regions, where interactions take place between the virus and the host immune system. The sequence encoding epitope proteins have a significant effect on the virus's ability to interact with elements of the immune system, which is particularly important in view of its strong tropism for immune cells. Battilani et al. [22] describe a change in the epitope sequence of CPV-2, which leads to the emergence of a new genetic variant of the parvovirus - N/ D426E. The new strain also attacks cats, despite the presence of neutralizing antibodies. Moreover, the new isolate displays a tendency towards co-infections. Polymorphism of the same amino acid makes it possible to distinguish variants CPV-2a and CPV-2b.

Differences in the nucleotide sequence between isolates from wild and farmed animals determine the phylogenetic relationships between the variants obtained. It is worth noting the close relationship between the variant infecting wild animals and the Pullman strain (nucleotide sequence similarity between the wild variants and the Pullman strain averages $97 \%$, while in the case of the variant infecting farmed animals similarity to the Pullman strain is only $92 \%$ ), which has low virulence (mortality rate of $30-50 \%$, development of clinical symptoms in 50-70\% of infected animals) [23]. Infection with this strain may be persistent or transient, without characteristic symptoms. Differences in the sequence of epitope sites between wild and farmed isolates may entail changes in the clinical picture of the disease. The variant infecting farmed animals is much more closely related to the highly virulent strains. The virus attacking the free-living population is much less aggressive, which is conducive to its spread in the population.

The high level of anti-AMDV antibodies in the free-living mink is confirmed by Farid [6], who observed that the virus also infects other predatory animals, such as foxes and coyotes, as well as rodents, such as squirrels. Yamaguchi and Macdonald [24], analysing the presence of anti-AMDV antibodies in southern England, obtained a result indicating contact with the pathogen in over $50 \%$ of free-living mink. The virus, causing a milder disease course, can circulate widely in a wild population, which is confirmed by the high percentage of mink in which infection with the virus was confirmed. At the same time, as the pathogen is characterized by a low mortality rate, it does not significantly decrease the population and becomes established in it.

\section{CONCLUSION}

The results confirm the presence of the AMD virus in both farmed and wild animals, but comparison of amino acid and nucleotide sequences reveals genetic dissimilarity between the populations. Variants of the virus infecting the two groups may have a common origin, but they are currently two separate groups, with characteristic differences making it possible to recognize their genotype. The results do not allow the possibility to be ruled out that the virus circulates between the wild and farmed population, but the high genetic dissimilarityof the virus in the two groups may indicate that the original sources of infection were different and independent. Phylogenetic analysis based on the sequence of the protein VP2 containing epitope fragments indicates that the virus attacking free-living individuals is less pathogenic, so that it becomes widespread and established among wild populations.

\section{Acknowledgements}

This study was been funded by the Polish National Science Centre (Project N N308 599939).

\section{REFERENCES}

1. Knuuttila A, Uzcategui N, Kankkonen J, Vapalahti O, Kinnunen, P. Molecular epidemiology of Aleutian mink disease virus in Finland. Vet Microbiol. 2009; 133: 229-238. [Crossref]

2. Reichert M, Kostro K. Effect of persistent infection of mink with Aleutian mink disease virus on reproductive failure. Bull Vet Inst Pulawy. 2014; 58:369-373. [Crossref] 
3. Hadlow WJ, Race RE, Kennedy RC. Comparative pathogenicity of four strains of Aleutian disease virus for pastel and sapphire mink. Infect Immun. 1983; 41: 1016-1023.

4. Bloom ME, Alexandersen S, Perryman S, Lechner D, Wolfinbarger JB. Nucleotide sequence and genomic organization of Aleutian mink disease parvovirus (ADV): sequence comparisons between a nonpathogenic and a pathogenic strain of ADV. J Virol. 1988; 62: 2903-2915.

5. Reichert M, Kostro K. NS1 gene based molecular characteristics of Aleutian mink disease virus circulating in Poland. Bull Vet Inst Pulawy. 2014; 58:187-191. [Crossref]

6. Farid AH. Aleutian mink disease virus in furbearing mammals in Nova Scotia, Canada. Acta Vet Scand. 2013; 55: https://doi.org/10.1186/17510147-55-10

7. Fournier-Chambrillon C, Aasted B, Perrot A, Pontier D, Sauvage F, Artois M, et al. Antibodies to aleutian mink disease parvovirus in freeranging European mink (Mustela lutreola) and other small carnivores from Southwestern France. J Wildl Dis. 2004; 40: 394-402. [Crossref

8. Nituch LA, Bowman J, Wilson PJ, Schulte-Hostedde AI. Aleutian mink disease virus in striped skunks (Mephitis mephitis): evidence for cross-species spillover. J Wildl Dis. 2015; 51: 389-400. [Crossref]

9. Jepsen JR, d'Amore F, Baandrup U, Clausen MR, Gottschalck E, Aasted B. Aleutian Mink Disease Virus and Humans. Emerg Infect Dis. 2009; 15: 2040-2042. [Crossref]

10. Leimann A, Knuuttila A, Maran T, Vapalahti O, Saarma U. Molecular epidemiology of Aleutian mink disease virus (AMDV) in Estonia, and a global phylogeny of AMDV. Virus Res. 2015; 199: 56-61. [Crossref]

11. McKenna R, Olson NH, Chipman PR, Baker TS, Booth TF, Christensen J, et al. Three-dimensional structure of Aleutian mink disease parvovirus: Implications for disease pathogenicity. J Virol. 1999; 73: 6882-6891.

12. Gottschalck E, Alexandersen S, Cohn A, Poulsen LA, Bloom ME, Aasted B. Nucleotide sequence analysis of Aleutian mink disease parvovirus shows that multiple virus types are present in infected mink. J Virol. 1991; 65: 4378-4386.

13. Oie KL, Durrant G, Wolfinbarger JB, Martin D, Costello F, Perryman $S$, et al. Relationship between capsid protein (VP2) sequence and pathogenicity of Aleutian mink disease parvovirus (ADV): A possible role for raccoons in the transmission of ADV infections. J Virol. 1996; 70: $852-861$.

14. Allison AB, Harbison CE, Pagan I, Stucker KM, Kaelber JT, Brown JD, et al. Role of Multiple Hosts in the Cross-Species Transmission and Emergence of a Pandemic Parvovirus. J Virol. 2012; 86: 865-872. [Crossref]

15. Clegg SR, Coyne KP, Dawson S, Spibey N, Gaskell RM, Radford AD. Canine parvovirus in asymptomatic feline carriers. Vet. Microbiol. 2012; 157: 78-85. [Crossref]

16. Manas S, Cena JC, Ruiz-Olmo J, Palazon S, Domingo M, Wolfinbarger $\mathrm{JB}$, et al. Aleutian mink disease parvovirus in wild riparian carnivores in Spain. J Wildl Dis. 2001; 37: 138-144. [Crossref]

17. Costello F, Steenfos N, Jensen KT, Christensen J, Gottschalck E, Holm A, et al. Epitope mapping of Aleutian Mink Disease Parvovirus virion protein VP1 and 2. Scand. J Immunol. 1999; 49: 347-354. [Crossref]

18. Jahns H, Daly P, McElroy MC, Sammin DJ, Bassett HF, Callanan JJ. Neuropathologic features of Aleutian disease in farmed mink in Ireland and molecular characterization of Aleutian mink disease virus detected in brain tissues. J Vet Diag Invest. 2010; 22: 101-105. [Crossref]

19. Battilani M, Scagliarini A, Ciulli S, Morganti L, Prosperi S. High genetic diversity of the VP2 gene of a canine parvovirus strain detected in a domestic cat. Virology 2006; 352: 22-26. [Crossref]

20. Majer-Dziedzic B, Jakubczak A, Zietek J. Phylogenetic analysis of canine parvovirus CPV-2 strains and its variants isolated in Poland. Pol J Vet Sci. 2011; 14: 379-384. [Crossref]

21. Spibey N, Greenwood NM, Sutton D, Chalmers WSK, Tarpey I. Canine parvovirus type 2 vaccine protects against virulent challenge with type 2c virus. Vet Microbiol. 2008; 128: 48-55. [Crossref]

22. Battilani M, Gallina L, Vaccari F, Morganti L. Co-infection with multiple variants of canine parvovirus type 2 (CPV-2). Vet Res Commun. 2007; 31: 209-212. [Crossref]

23. Alexandersen S, Larsen S, Aasted B, Uttenthal A, Bloom ME, Hansen M. Acute interstitial pneumonia in mink kits inoculated with defined isolates of Aleutian mink disease parvovirus. Vet Pathol. 1994; 31: 216-228. [Crossref]

24. Yamaguchi N, Macdonald DW. Detection of Aleutian disease antibodies in feral American mink in southern England. Vet Rec. 2001; 149:485488. [Crossref] 